\title{
Digestibilidade dos aminoácidos do milho, farelo de soja e gérmen integral de milho em galos e frangos de corte cecectomizados
}

\author{
Alexandre Barbosa de Brito ${ }^{1}$, José Henrique Stringhini ${ }^{2,3}$, Suzany Aparecida Gomes Xavier ${ }^{1}$, \\ Elisabeth Gonzales ${ }^{2}$, Nadja Susana Mogyca Leandro ${ }^{2,3}$, Marcos Barcellos Cafée,3 \\ 1 Poli-Nutri Alimentos, Osasco, SP. \\ 2 Departamento de Produção Animal, Escola de Veterinária, Universidade Federal de Goiás, Caixa Postal 131, 74001-070, Goiânia, GO. \\ ${ }^{3}$ Bolsista CNPq.
}

RESUMO - Este experimento foi conduzido para avaliar a digestibilidade dos aminoácidos do milho, farelo de soja e gérmen integral de milho em galos e frangos de corte cecectomizados. Foram utilizados 16 galos Lohmann-LSL com 45 semanas de idade, 40 frangos de corte machos AgRoss 508, sendo 20 com 21 dias de idade e outros 20 com 42 dias de idade, todos cecectomizados. Adotou-se delineamento inteiramente casualizado com três categorias animais (galos; frangos aos 21 dias; e frangos aos 42 dias de idade) para cada alimento avaliado e cada ave considerada uma unidade experimental. O ensaio durou 84 horas: nas 36 horas iniciais, as aves foram submetidas a jejum e nas 48 horas subsequentes, à ingestão forçada dos alimentos, feita com sonda esofágica introduzida diretamente no inglúvio das aves. As excretas produzidas foram colhidas duas vezes ao dia nas 48 horas subseqüentes. Os valores de aminoácidos digestíveis verdadeiros determinados para o milho e gérmen integral de milho determinados com frangos submetidos ao procedimento experimental aos 21 dias de idade foram inferiores aos do grupo controle (galos). Contudo, os mesmos resultados não foram observados para o farelo de soja. O aproveitamento de aminoácidos foi maior nos frangos submetidos ao procedimento experimental aos 42 dias de idade em comparação aos do grupo controle (galos adultos), independentemente do alimento avaliado. O teor de aminoácidos digestíveis verdadeiros totais obtidos foi de 7,24; 6,25 e 7,33\% para o milho, 9,66; 9,14 e 9,91\% para o gérmen integral de milho e 41,82; 41,78 e 42,02\% para o farelo de soja, valores determinados com galos, frangos aos 21 e aos 42 dias de idade, respectivamente. Observou-se que, com o amadurecimento do trato digestório, aumenta o aproveitamento proteico em aves que consomem milho e gérmen integral de milho.

Palavras-chave: digestibilidade, fase inicial, maturação fisiológica, nutrição, trato gastrintestinal

\section{Digestibility of amino acids from corn, soybean meal and corn germ meal in cecectomized roosters and broilers}

\begin{abstract}
This experiment was carried out to evaluate the digestibility of the amino acids from corn, soybean meal and corn germ meal in cecectomized roosters and broilers. The experiment used sixteen Lohmann-LSL roosters with 45 weeks of age, 20 AgRoss 508 male broilers with 21 days of age and 20 other male broilers of same line, with 42 days of age, all of them cecectomized. A completely randomized arrangement with three animal categories (roosters; chickens at 21 and 42 days of age) was adopted for each feedstuff analyzed. Each bird represented an experimental unit. The trial had a duration of 84 hours; in the first 36 hours roosters and chickens were submitted to fasting for intestinal cleaning. After this, birds were forced to ingest 30 grams of each ingredient with an esophageal probe, introduced directly into the crop. During the subsequent 48 hours, the excreta produced was collected twice a day. The values for true digestible amino acids were reduced for corn and full-fat corn germ meal when determined with broilers submitted to the experimental procedures at 21 days of age compared to the control group (adult cockerels). But, the same results were not been observed for soybean meal. In general, the true digestible amino acid values were higher when determined with broilers at 42 days of age compared to adult cockerels. The total amount of true digestible amino acids determined were 7.24; 6.25 and 7.33\% for corn, 9.66; 9.14 and $9.91 \%$ for corn germ meal and 41.82; 41.78 and $42.02 \%$ for soybean meal, values determined with roosters, and broilers at 21 and 42 days of age, respectively. It was observed that as the gastrointestinal tract is mature, the amino acid digestibility of birds that consumed corn and corn germ meal is enhanced.
\end{abstract}

Key Words: digestibility, gastrointestinal tract, nutrition, physiologic maturation, starter phase 


\section{Introdução}

A inclusão dos alimentos em dietas para aves baseia-se em tabelas de composição nutricional, que expressam as necessidades dos animais e o valor nutritivo dos alimentos. Torna-se importante quantificar a composição nutricional dos alimentos com a metodologia mais adequada para que a formulação das dietas seja mais precisa, especialmente o nível de aminoácidos e sua digestibilidade (Borges et al., 2003; Oliveira Neto \& Oliveira, 2009).

Existem alguns métodos utilizados para determinação da digestibilidade dos aminoácidos. Entre estes métodos incluem-se ensaios de crescimento, ensaios químicos e microbiológicos, quantificação de aminoácidos do sangue e o balanço nutricional, no qual os aminoácidos provenientes da coleta ileal ou das excretas, são mensurados. Porém, cada método apresenta princípios e limitações que resultam em diferentes valores (Engster et al., 1985; Rostagno et al., 1995; Brito et al., 2009).

O ensaio apresentado por Sibbald (1976) para estimativa da energia metabolizável verdadeira pode ser utilizado para determinação do conteúdo de aminoácidos digestíveis. Likuski \& Dorell (1978) citam que esse método é rápido e de baixo custo. Engster et al. (1985) mencionam como ponto falho do método, o desconhecimento da contribuição dos aminoácidos microbianos na excreta e a possível influência dos aminoácidos urinários e endógenos no processo de determinação. Atualmente, estes fatores são corrigidos pelo uso de galos adultos cecectomizados e parcelas de animais em jejum para determinação das perdas endógenas e metabólicas (Sakomura \& Rostagno, 2007) ou mesmo com utilização de dietas isentas de proteína (Brito et al., 2009).

A utilização dos valores de aminoácidos digestíveis nas formulações de rações, ainda encontra restrições na avicultura comercial, pois a metodologia tradicional para a determinação destes dados recomenda o uso de galos adultos cecectomizados da raça Leghorn ou provenientes das linhagens de postura. A adoção destes valores para frangos de corte, sobretudo nas fases iniciais de criação, pode gerar dúvidas em virtude das diferenças na maturação do trato digestório (Dale \& Fuller, 1986).

A escolha de galos adultos foi aceita pelos pesquisadores devido a sua rusticidade, pois o processo de determinação dos aminoácidos digestíveis possui uma execução laboriosa representada pela etapa que exige intervenção cirúrgica para retirada dos cecos (denominada cecectomia ou tiflectomia). Esta intervenção objetiva eliminar a produção dos aminoácidos exógenos pela microflora cecal (Pupa et al., 1998). Todavia, experimentos realizados no Setor de Avicultura do Departamento de Produção Animal EV/UFG comprovaram que a intervenção cirúrgica na região abdominal de frangos de corte é possível mesmo no primeiro dia de vida (Brito et al., 2002).

Objetivou-se com este experimento avaliar a digestibilidade dos aminoácidos do milho, farelo de soja e do gérmen integral de milho (GIM), obtidos com galos e frangos de corte cecectomizados.

\section{Material e Métodos}

Este experimento foi conduzido no aviário experimental do Setor de Avicultura da Escola de Veterinária da Universidade Federal de Goiás (EV/UFG). Foram utilizados 16 galos da linhagem Lohmann-LSL com 45 semanas de idade e 1.555, $6 \pm$ 94,7 g, 20 frangos de corte machos da linhagem AgRoss 508 com 21 dias de idade e peso médio de $861,7 \pm 15,6$ g e 20 frangos de corte da mesma linhagem, com 42 dias de idade e 2.494,6 $+119,4$ g. Para obtenção dos dados de digestibilidade dos aminoácidos, utilizou-se o delineamento inteiramente casualizado com três categorias animais: galos; frangos com 21 dias de idade; e frangos com 42 dias de idade, para cada alimento avaliado. Cada animal foi considerado uma repetição: sendo quatro galos por alimento, cinco frangos de 21 dias de idade e cinco frangos de 42 dias de idade.

As aves foram alojadas em gaiolas individuais de aço galvanizado respeitando o espaço de $1.125 \mathrm{~cm}^{2} /$ ave. Foi alojada uma ave por gaiola com $0,45 \mathrm{~m}$ de comprimento, $0,25 \mathrm{~m}$ de largura e $0,40 \mathrm{~m}$ de altura. Todas as gaiolas possuíam bandejas coletoras de excretas.

Para realização do experimento, todas as aves foram submetidas ao procedimento de cecectomia proposto por Pupa et al. (1998), sendo os frangos cecectomizados aos 7 dias e os galos com 30 semanas de idade.

Foram avaliados os teores de aminoácidos digestíveis do milho, do gérmen integral do milho (GIM) e do farelo de soja, utilizando o método de alimentação forçada, descrito por Sibbald (1976). A duração do ensaio foi de 84 horas e nas primeiras 36 horas os galos e os frangos foram submetidos a jejum para a limpeza do trato gastrintestinal e nas 48 horas seguintes forçados a ingerir $30 \mathrm{~g}$ dos alimentos avaliados, divididos em duas porções de $15 \mathrm{~g}$, sendo a primeira porção ingerida no período da manhã do terceiro dia experimental e as outras $15 \mathrm{~g}$ no período da tarde do mesmo dia. No mesmo período, foram mantidos, cinco frangos de cada idade e quatro galos em jejum, para colheita de excretas para determinação dos aminoácidos endógenos e metabólicos.

Em todo o período experimental, realizou-se a coleta total de excretas, realizadas duas vezes ao dia, por 48 horas, conforme metodologia descrita por Sakomura \& Rostagno 
(2007). As excretas foram acondicionadas em sacos plásticos, identificados e armazenados em congelador com temperatura de $-16^{\circ} \mathrm{C}$. Amostras de alimentos e excretas foram encaminhadas ao Laboratório de Nutrição Animal da EVZ/UFG para processamento e análise dos teores de matéria seca (MS) e proteína bruta (PB) dos alimentos e das excretas. Para determinação dos teores de aminoácidos totais foi utilizada a cromatografia líquida de alta precisão (HPLC) realizada no Laboratório da Degussa-Hüss (Alemanha).

Com base nos resultados obtidos, os teores de aminoácidos totais dos alimentos, das excretas e endógenos foram tabulados e serviram como base para determinação dos teores de aminoácidos digestíveis verdadeiros, seguindo a metodologia descrita por Matterson et al. (1965), Sibbald (1976), Albino et al. (1992) e Sakomura \& Rostagno (2007).
A análise estatística foi realizada pelo programa SAEG/UFV (2000), sendo utilizado o teste Tukey a 5\% de probabilidade para a comparação das médias.

\section{Resultados e Discussão}

Ao analisar os valores de aminoácidos digestíveis verdadeiros determinados para o milho (Tabela 1) e para o gérmen integral de milho (Tabela 2), verificou-se diferença $(\mathrm{P}<0,05)$ nos valores obtidos para digestibilidade de aminoácidos com frangos submetidos ao procedimento experimental na fase inicial (21 dias de idade) quando comparados com o grupo controle (galos). Esse achado reflete o efeito do amadurecimento do trato digestório, que permite melhor aproveitamento dos aminoácidos e da

Tabela 1 - Valores dos aminoácidos digestíveis verdadeiros do milho obtido com galos e frangos cecectomizados

\begin{tabular}{|c|c|c|c|c|}
\hline Aminoácidos & Galos & Frangos com 21 dias & Frangos com 42 dias & $\mathrm{CV}, \%$ \\
\hline Metionina, \% & $0,152 \mathrm{a}$ & $0,139 b$ & $0,152 \mathrm{a}$ & 2,18 \\
\hline Cistina, \% & $0,174 \mathrm{a}$ & $0,145 b$ & $0,179 \mathrm{a}$ & 4,87 \\
\hline Metionina + cistina, \% & $0,327 \mathrm{a}$ & $0,284 b$ & $0,331 \mathrm{a}$ & 3,59 \\
\hline Lisina, \% & $0,268 a$ & $0,234 b$ & $0,280 a$ & 3,71 \\
\hline Treonina, \% & $0,286 a$ & $0,217 b$ & $0,288 a$ & 4,78 \\
\hline Arginina, \% & $0,449 a$ & $0,415 b$ & $0,454 \mathrm{a}$ & 2,12 \\
\hline Isoleucina, \% & $0,266 \mathrm{a}$ & $0,234 b$ & $0,268 \mathrm{a}$ & 3,36 \\
\hline Leucina, \% & $0,846 a$ & $0,785 b$ & $0,848 a$ & 2,02 \\
\hline Valina, \% & $0,386 a$ & $0,332 b$ & $0,388 a$ & 3,67 \\
\hline Histidina, \% & $0,248 \mathrm{a}$ & $0,215 b$ & $0,255 a$ & 2,79 \\
\hline Fenilalanina, \% & $0,341 \mathrm{a}$ & $0,298 b$ & $0,345 a$ & 2,87 \\
\hline Glicina, \% & $0,271 \mathrm{a}$ & $0,072 b$ & $0,302 \mathrm{a}$ & 5,81 \\
\hline Serina, \% & $0,362 \mathrm{a}$ & $0,312 b$ & $0,369 a$ & 3,83 \\
\hline Prolina, \% & $0,759 a$ & $0,652 b$ & $0,760 \mathrm{a}$ & 2,83 \\
\hline Alanina, \% & $0,563 a$ & $0,508 b$ & $0,563 a$ & 2,69 \\
\hline Ácido aspártico, \% & $0,523 a$ & $0,448 b$ & $0,527 \mathrm{a}$ & 3,26 \\
\hline Ácido glutâmico, \% & $1,342 \mathrm{a}$ & $1,240 b$ & $1,355 a$ & 1,91 \\
\hline
\end{tabular}

Valores em base de matéria natural.

${ }^{\mathrm{ab}}$ Letras diferentes na mesma linha indicam diferença $(\mathrm{P}<0,05)$ pelo teste Tukey.

$\mathrm{CV}=$ Coeficiente de variação.

Tabela 2 - Valores dos aminoácidos digestíveis verdadeiros do gérmen integral de milho obtido com galos e frangos cecectomizados

\begin{tabular}{|c|c|c|c|c|}
\hline Aminoácidos & Galos & Frangos com 21 dias & Frangos com 42 dias & $\mathrm{CV}, \%$ \\
\hline Metionina, \% & $0,204 \mathrm{ab}$ & $0,200 \mathrm{~b}$ & $0,206 a$ & 1,24 \\
\hline Cistina, \% & $0,230 \mathrm{a}$ & $0,215 b$ & $0,232 \mathrm{a}$ & 3,08 \\
\hline Metionina + cistina, $\%$ & $0,427 a$ & $0,415 b$ & $0,437 \mathrm{a}$ & 2,12 \\
\hline Lisina, \% & $0,538 a$ & $0,523 b$ & $0,549 a$ & 1,79 \\
\hline Treonina, \% & $0,411 \mathrm{ab}$ & $0,404 b$ & $0,424 \mathrm{a}$ & 1,29 \\
\hline Arginina, \% & $0,838 \mathrm{a}$ & $0,833 b$ & $0,850 \mathrm{a}$ & 0,88 \\
\hline Isoleucina, \% & $0,338 \mathrm{ab}$ & $0,325 b$ & $0,345 a$ & 2,82 \\
\hline Leucina, \% & $0,851 \mathrm{a}$ & $0,838 b$ & $0,864 \mathrm{a}$ & 1,26 \\
\hline Valina, \% & $0,555 \mathrm{ab}$ & $0,542 b$ & $0,564 \mathrm{a}$ & 1,61 \\
\hline Histidina, \% & $0,336 a$ & $0,330 \mathrm{~b}$ & $0,348 a$ & 2,12 \\
\hline Fenilalanina, \% & $0,448 a$ & $0,376 b$ & $0,455 a$ & 3,37 \\
\hline Glicina, \% & $0,480 \mathrm{a}$ & $0,472 b$ & $0,483 a$ & 4,47 \\
\hline Serina, \% & $0,508 \mathrm{a}$ & $0,441 b$ & $0,525 a$ & 2,92 \\
\hline Prolina, \% & $0,745 a$ & $0,654 b$ & $0,761 \mathrm{a}$ & 5,55 \\
\hline Alanina, \% & $0,717 \mathrm{a}$ & $0,653 b$ & $0,726 a$ & 1,56 \\
\hline Ácido aspártico, \% & $0,855 \mathrm{a}$ & $0,772 \mathrm{c}$ & $0,870 \mathrm{a}$ & 1,90 \\
\hline Ácido glutâmico, \% & $1,623 b$ & $1,560 \mathrm{c}$ & $1,654 \mathrm{a}$ & 0,54 \\
\hline
\end{tabular}

Valores em base de matéria natural.

${ }^{a b c}$ Letras diferentes na mesma linha indicam diferença pelo teste Tukey $(P<0,05)$.

$\mathrm{CV}=$ Coeficiente de variação. 
proteína desses alimentos. Contudo, os mesmos resultados não foram observados $(\mathrm{P}>0,05)$ para o farelo de soja (Tabela 3) e isso indica diferença no aproveitamento nutricional de aves com idades distintas para diferentes ingredientes.

O aproveitamento de aminoácidos foi maior $(\mathrm{P}<0,05)$ nos frangos submetidos ao procedimento experimental aos 42 dias de idade em comparação aos do grupo controle (galos adultos), independentemente do alimento avaliado (Figura 1).

A provável explicação para essa diferença no padrão digestivo dos concentrados energéticos e do farelo de soja, em aves na fase inicial de vida, relaciona-se à característica estrutura da proteína dos ingredientes avaliados.

Diferentes estruturas proteicas presentes em alimentos distintos determinam taxas de digestibilidade variáveis para o conteúdo aminoacídico. Esta diferença estrutural está, dentre outros fatores, relacionado com a natureza das inter-relações dos aminoácidos que as compõe (Farrell et al., 1999).

Este resultado pode ser explicado pela maturação fisiológica do trato gastrintestinal de frangos, que ocorre antes dos 42 dias de idade, uma vez que estas aves são, pela seleção genética, mais eficientes no aproveitamento de nutrientes que as de postura.

À eclosão, o sistema digestório da ave está anatomicamente completo, mas a capacidade de digestão e absorção ainda está imatura em comparação à ave adulta. Assim, após a eclosão, o trato gastrintestinal sofre grandes alterações, como a maturação funcional do intestino, que envolve mudanças morfológicas e fisiológicas com aumento na área de superfície de digestão e de absorção. As alterações morfológicas mais significativas são: aumento das secreções enzimáticas, do comprimento do intestino, na altura e na densidade dos vilos e, consequentemente, no número de enterócitos, de células caliciformes e de células enteroendócrinas (Maiorka et al., 2002).
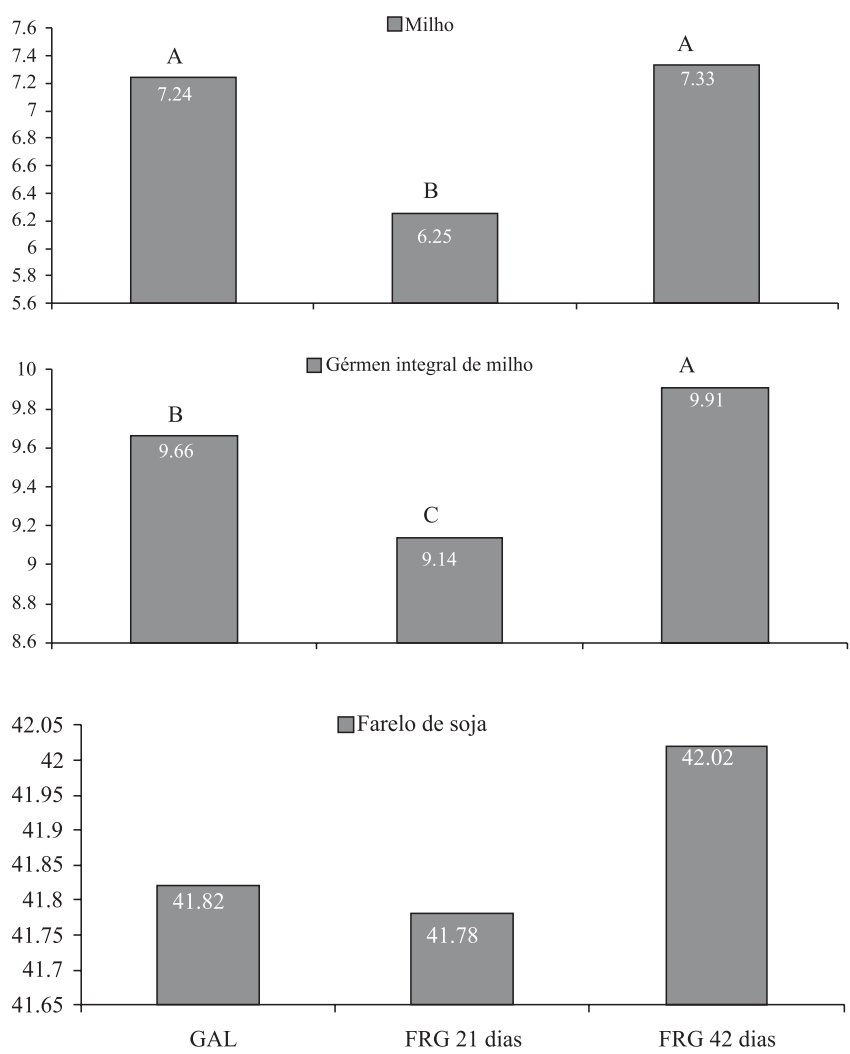

${ }^{\mathrm{ab}}$ Indicam diferença pelo teste Tukey $(\mathrm{P}<0,05)$

Figura 1 - Total de aminoácidos digestíveis verdadeiros do milho, gérmen integral de milho e farelo de soja, com base na matéria natural, em galos e frangos cecectomizados.

Tabela 3 - Valores dos aminoácidos digestíveis verdadeiros do farelo de soja obtido com galos e frangos cecectomizados

\begin{tabular}{|c|c|c|c|c|}
\hline Aminoácidos & Galos & Frangos com 21 dias & Frangos com 42 dias & $\mathrm{CV}, \%$ \\
\hline Metionina, \% & 0,644 & 0,644 & 0,646 & 0,12 \\
\hline Cistina, \% & $0,660 \mathrm{ab}$ & $0,659 b$ & $0,667 \mathrm{a}$ & 0,38 \\
\hline Metionina + cistina, \% & $1,304 b$ & $1,303 b$ & $1,313 \mathrm{a}$ & 0,23 \\
\hline Lisina, \% & 2,827 & 2,826 & 2,830 & 0,10 \\
\hline Treonina, \% & $1,748 \mathrm{a}$ & $1,737 b$ & $1,750 \mathrm{a}$ & 0,29 \\
\hline Arginina, \% & $3,225 a b$ & $3,221 b$ & $3,230 a$ & 0,08 \\
\hline Isoleucina, \% & 2,057 & 2,054 & 2,061 & 0,19 \\
\hline Leucina, \% & 3,419 & 3,415 & 3,424 & 0,20 \\
\hline Valina, \% & 2,116 & 2,110 & 2,119 & 0,23 \\
\hline Histidina, \% & 1,153ab & $1,146 \mathrm{~b}$ & $1,157 \mathrm{a}$ & 0,23 \\
\hline Fenilalanina, \% & $2,207 \mathrm{ab}$ & $2,200 b$ & $2,213 a$ & 0,21 \\
\hline Glicina, \% & $1,831 \mathrm{ab}$ & $1,800 \mathrm{~b}$ & $1,869 \mathrm{a}$ & 1,18 \\
\hline Serina, \% & $2,364 \mathrm{a}$ & $2,354 b$ & $2,368 a$ & 0,19 \\
\hline Prolina, \% & $2,240 \mathrm{ab}$ & 2,234 & 2,252 & 0,30 \\
\hline Alanina, \% & 1,983 & $1,980 a$ & $1,985 a$ & 0,25 \\
\hline Ácido aspártico, \% & $5,109 a b$ & $5,103 b$ & $5,121 \mathrm{a}$ & 0,15 \\
\hline Ácido glutâmico, \% & $8,278 \mathrm{ab}$ & $8,293 b$ & $8,306 a$ & 0,12 \\
\hline
\end{tabular}

Valores em base de matéria natural.

${ }^{\mathrm{ab}}$ Letras diferentes na mesma linha indicam diferença $(\mathrm{P}<0,05)$ pelo teste Tukey.

$\mathrm{CV}=$ Coeficiente de variação. 
As alterações fisiológicas, por sua vez, estão relacionadas com o aumento na capacidade de digestão e de absorção do intestino, que ocorrem pela maior produção de enzimas digestivas pancreáticas e de membrana (Nitsan et al., 1991), bem como de transportadores de membrana (Noy \& Sklan, 1997).

Esse desenvolvimento acentuado na capacidade funcional do trato gastrintestinal logo após a eclosão parece ser comum às aves domésticas, ocorrendo pequenas variações entre as diferentes linhagens. Em poedeiras comerciais, o aumento na altura dos vilos e profundidade de cripta é mais intenso no duodeno nos primeiros seis dias de vida pós eclosão e aos 10 dias para o jejuno e íleo (Uni et al., 1995).

Em frangos, por sua vez, o aumento mais acentuado na altura dos vilos do duodeno começa no 170 으 dia de incubação até o $7^{0}$ dia pós eclosão. No jejuno e no íleo o crescimento continua até o $14^{\circ}$ dia, resultando em aumento no número de enterócitos por vilo. Nesse período, a profundidade de cripta também aumenta, sendo maior no duodeno e menor no íleo, porém, a maturação do trato gastrintestinal se estabelece aos 16 dias de idade em frangos de corte (Nitsan et al., 1991; Uni et al., 1996).

\section{Conclusões}

Em aves, com o amadurecimento do trato digestório, ocorre aumento no aproveitamento dos aminoácidos do milho e o gérmen integral de milho.

\section{Agradecimentos}

Ao CNPq, GEM Alimentos e Evonik-Degussa, pelos recursos materiais e financeiros à realização do projeto.

\section{Referências}

ALBINO, L.F.T.; ROSTAGNO, H.S.; SANT'ANNA, R. et al. Determinação dos valores de aminoácidos metabolizáveis e proteína digestível de alimentos para aves. Revista Brasileira de Zootecnia, v.21, n.6, p.1059-1068, 1992.

BORGES, F.M.O.; ROSTAGNO, H.S.; SAAD, C.E.P. et al. Avaliação dos coeficientes de digestibilidade dos aminoácidos do grão de trigo e seus subprodutos para frangos de corte utilizando diferentes metodologias. Arquivo Brasileiro de Medicina Veterinária e Zootecnia, v.55, n.6, p.68-72, 2003.

BRITO, A.B.; CRUZ, C.P.; CUNHA, W.P. et al. Métodos de síntese da incisão cirúrgica em pintos neonatos deutectomizados. Revista Brasileira de Ciência Avícola, v.4, supl.4, p.90, 2002.

BRITO, C.O.; ALBINO, L.F.T.; ROSTAGNO, H.S. et al. Dieta aminoacídica na determinação da perda endógena ileal de frangos de corte: uma proposta metodológica. Revista Brasileira de Zootecnia, v.38, n.11, p.2161-2166, 2009.

DALE, N.M.; FULLER, H.L. Repetability of true metabolizable energy versus nitrogen corrected true metabolizable energy values. Poultry Science, v.66, n.2, p.352-354, 1986.

ENGSTER, H.M.; CAVE, N.A.; LIKUSKI, H. A collaborative study to evaluate a precision-fed rooster assay for true amino acid availability in feed ingredients. Poultry Science, v.64, n.3, p.487-498, 1985.

FARRELL, D.J.; MANNION, P.F.; PEREZ-MALDONADO, R.A. A comparison of total and digestible amino acids in diets for broilers and layers. Animal Feed Science and Technology, v.82, n.1, p.131-142, 1999.

LIKUSKI, H.J.A.; DORRELL, H.G. A bioassay for rapid determinations of amino acid availability values. Poultry Science, v.57, n.12, p.1658-1660, 1978.

MAIORKA, A.; BOLELI, I.C.; MACARI, M. Desenvolvimento e reparo da mucosa intestinal. In: MACARI, M.; FURLAN, R.L.; GONZALES, E. (Eds.) Fisiologia aviária aplicada a frangos de corte. 2.ed. Jaboticabal: FUNEP, 2002. p.113-124.

MATTERSON, L.D.; POTTER, L.M.; STUTZ, M.W. et al. The metabolizable energy of feeds ingredients for chickens. Connecticut: Uniconn Press, 1965. 11p.

NITSAN, Z.; DUNNINGTON, E.A.; SIEGEL, P.B. Organ growth and digestive enzymes levels to fifteen days of age in lines of chickens differing in body weight. Poultry Science, v.70, n.12, p.2040-2048, 1991

NOY, Y.; SKLAN, D. Posthatch development of poultry. Journal of Applied Poultry Research, v.6, n.3, p.344-354, 1997.

OLIVEIRA NETO, A.R.; OLIVEIRA, W.P. Aminoácidos para frangos de corte. Revista Brasileira de Zootecnia, v.38, p.205-208, 2009 (supl. especial).

PUPA, J.M.R.; LEÄO, M.I.; CARVALHO, A.U. et al. Cecectomia em galos sob anestesia local e incisäo abdominal Arquivo Brasileiro de Medicina Veterinária e Zootecnia, v.50, n.5, p.531-535, 1998.

ROSTAGNO, H.S.; PUPA, J.M.R.; PACK, M. Diet formulation for broilers based on total versus digestible amino acids. Journal of Applied Poultry Research, v.4, n.1, p.293-299, 1995.

SAKOMURA, N.K.; ROSTAGNO, H.S. Métodos de pesquisa em nutrição de monogástricos. Jaboticabal: FUNEP, 2007. 283p.

SIBBALD, I.R. A bioassay for true metabolizable energy in feedingstuffs. Poultry Science, v.55, n.2, p.303-308, 1976.

UNIVERSIDADE FEDERAL DE VIÇOSA - UFV. SAEG - Sistema de análises estatísticas e genéticas. Versão 7.1. Viçosa, MG: FUNARBE, 2000. 150p. [Manual do usuário].

UNI, Z.; NOY, Y.; SKLAN, D. Posthatch changes in morfology and function of the small intestines in heavy and light strain chicks. Poultry Science, v.74, n.10, p.1622-1629, 1995.

UNI, Z.; NOY, Y.; SKLAN, D. Development of the small intestine in heavy and light strain chicks before and after hatching. British Poultry Science, v.36, n.1, p.63-71, 1996. 